\title{
HIV-1 drug resistance genotyping from antiretroviral therapy (ART) naïve and first-line treatment failures in Djiboutian patients
}

\author{
Aden Elmi Abar ${ }^{1,2^{*}}$, Asma Jlizi ${ }^{2}$, Houssein Youssouf Darar ${ }^{3}$, Mohamed Ali Ben Hadj Kacem ${ }^{2}$ and Amine Slim ${ }^{2}$
}

\begin{abstract}
In this study we report the prevalence of antiretroviral drug resistant HIV-1 genotypes of virus isolated from Djiboutian patients who failed first-line antiretroviral therapy (ART) and from ART naïve patients.

Patients and methods: A total of 35 blood samples from 16 patients who showed first-line ART failure (>1000 viral genome copies $/ \mathrm{ml}$ ) and 19 ART-naïve patients were collected in Djibouti from October 2009 to December 2009. Both the protease (PR) and reverse transcriptase (RT) genes were amplified and sequenced using National Agency for AIDS Research (ANRS) protocols. The Stanford HIV database algorithm was used for interpretation of resistance data and genotyping.
\end{abstract}

Results: Among the 16 patients with first-line ART failure, nine (56.2\%) showed reverse transcriptase inhibitor-resistant HIV-1 strains: two (12.5\%) were resistant to nucleoside (NRTI), one (6.25\%) to non-nucleoside (NNRTI) reverse transcriptase inhibitors, and six (37.5\%) to both. Analysis of the DNA sequencing data indicated that the most common mutations conferring drug resistance were M184V (38\%) for NRTI and K103N (25\%) for NNRTI. Only NRTI primary mutations K101Q, K103N and the PI minor mutation L10V were found in ART naïve individuals. No protease inhibitor resistant strains were detected. In our study, we found no detectable resistance in 44\% of all patients who experienced therapeutic failure which was explained by low compliance, co-infection with tuberculosis and malnutrition. Genotyping revealed that $65.7 \%$ of samples were infected with subtype C, $20 \%$ with CRF02_AG, 8.5\% with B, 2.9\% with CRF02_AG/C and 2.9\% with K/C.

Conclusion: The results of this first study about drug resistance mutations in first-line ART failures show the importance of performing drug resistance mutation test which guides the choice of a second-line regimen. This will improve the management of HIV-infected Djiboutian patients.

Virtual slides: The virtual slide(s) for this article can be found here: http://www.diagnosticpathology.diagnomx.eu/ vs/2051206212753973

Keywords: HIV-1 drug resistance, First-line antiretroviral therapy failure, Antiretroviral naive, Djibouti, Virological failure

\section{Background}

Since the discovery of human immunodeficiency virus (HIV) as the causative agent in 1983, the HIV-1 pandemic is characterized by an extensive variability and the circulation of numerous genotypes and recombinant forms (CRFs) $[1,2]$. Subtype $C$ is the most prevalent, estimated

\footnotetext{
* Correspondence: aden_elmi@yahoo.fr

'Laboratoire de la Caisse Nationale de Sécurité Sociale, Djibouti, Republic of Djibouti

${ }^{2}$ Laboratoire de Microbiologie, CHU Charles Nicolle, Tunis, Tunisie

Full list of author information is available at the end of the article
}

to represent $48 \%$ infections in the HIV-1 pandemic [3]. Subtype $\mathrm{C}$ is predominant particularly in south and east Africa [4]. This strongly contrasts with the situation in central Africa where a marked genetic heterogeneity is observed.

HIV-1 remains a crucial global health problem. Delivery of ART in low and middle income countries has required utilization of a public health approach in which standardized, rather than individualized, regimens are prescribed to very large numbers of HIV-1-infected individuals [5]. At present, the majority of individuals in these countries are initiating first-line therapy with a non-nucleoside

\section{Biomed Central}


reverse transcriptase inhibitor (NNRTI) and two nucleoside reverse transcriptase inhibitors (NRTI) [6].

The introduction of antiretroviral (ARV) therapy in resource-poor settings is effective in suppressing HIV-1 replication and prolonging life of infected individuals. Nevertheless, patients in routine clinical care experience sustain detectable viral replication even under potent combination therapy. Various factors underlie this failure to achieve viral suppression, but resistance to current medications has been increasingly recognized as an important factor. Rational choice of the NRTI component of second-line therapy should be based on patterns of resistance developed during first-line therapy [7].

Djibouti is the smallest country in east Africa. The estimated prevalence of HIV-1 infection was around $2.5 \%$ (2009). Since the introduction of antiretroviral therapy in 2004, no data exist on the epidemiology of drug resistance mutations and little was known about HIV-1 genotypes circulating in Djibouti. Data on drug resistance in the routine care setting are urgently required to check ART efficacy. The present study aims to characterize circulating HIV-1 subtypes and to identify drug resistance mutations in patients who first-line therapy failed (>1000 copies $/ \mathrm{mL})$ and antiretroviral-naive patients from Djibouti.

\section{Materials and methods}

\section{Population study and sample collection}

Between October and December 2009, the whole blood samples were collected in Djibouti city from 35 HIV-1 infected patients consulting at three health centers (Hôpital General Peltier, $\mathrm{N}=23$, Centre Yonis Thoussaint, $\mathrm{N}=9$ and Centre Paul Faure, $\mathrm{N}=3$ ). EDTA (ethylenediaminetetraacetic acid-anticoagulated) plasma specimens were obtained after centrifugation, and stored at $-80^{\circ} \mathrm{C}$ in aliquots for later assessment of HIV RNA viral-load and genotypic drug resistance testing. The ethical aspects of this study were approved by the local committee. For all participants, blood collection was performed after informed consent, under the supervision of local sanitary authorities.

\section{Viral load and CD4}

The CD3/CD4+ cells were enumerated by flowcytometry (BD FACSCount System) and the quantification of HIV-1 viral load (VL) was measured using NASBA, NucliSENS ${ }^{\circledR}$ EasyQ Assays (BioMerieux) at the central laboratory of "Hôpital General Peltier" in Djibouti.

The plasma samples were shipped to the Laboratory of Microbiology of "Charles Nicolle" Hospital (Tunis, Tunisia) for drug resistance genotyping tests.

\section{Drug resistance genotyping}

For Drug Resistance genotyping, the viral RNA was isolated from plasma samples using DSP virus RNA kit
(QIAGEN Inc.) and reverse transcribed to make complementary DNA (cDNA) copies using a cDNA synthesis kit the One Step RT-PCR (QIAGEN Inc). The reverse transcriptase (RT) and protease (PR) genes were amplified according to the ANRS consensus sets of primers: for the RT gene amplification, MJ3 and MJ4 primers were used for a first PCR (RT-PCR), and A(35) with NE1(35) as inner primers for nested PCR. For the protease gene amplification, 5'Prot1 and 3'Prot1 outer primers were used and the $5^{\prime} \operatorname{Prot} 2$ and 3 'Prot2 as inner primers: (ANRS: http://www.hivfrenchresistance. org/ANRS-procedures.pdf).

RT-PCR involved a reverse transcription step at $50^{\circ} \mathrm{C}$ for 30 minutes, followed by $95^{\circ} \mathrm{C}$ for 15 minutes before proceeding to 40 cycles of $95^{\circ} \mathrm{C}$ for 45 seconds, $50^{\circ} \mathrm{C}$ for 30 seconds and $72^{\circ} \mathrm{C}$ for 1 minute 30 seconds, with a final extension step of 10 minutes at $72^{\circ} \mathrm{C}$. The RT-PCR products were then subjected to nested PCR with the following cycling conditions: a denaturation step of 2 minutes at $95^{\circ} \mathrm{C}$, and then 35 cycles with 1 cycle consisting of $30 \mathrm{sec}-$ onds at $95^{\circ} \mathrm{C}, 30$ seconds at $55^{\circ} \mathrm{C}$ and 30 seconds at $72^{\circ} \mathrm{C}$ with a final extension at $72^{\circ} \mathrm{C}$ for 7 minutes.

PCR products $(5 \mu \mathrm{L})$ were resolved by electrophoresis on a $1.5 \%$ agarose gel GellyPhorLE, (Euroclone, UK). DNA bands were stained with RedSafe $e^{\mathrm{Tm}}$ Nucleid Acid Staining Solution [20,000 X] (iNtRON Biotechnology, Inc, Korea). They were then visualized in UV light to assess the presence of fragments of the expected length compared with the standard marker SharpMass ${ }^{\mathrm{Tw}} 50-D N A$ ladder (Euroclone, Wetherby, UK). The amplification products were purified using QIAquick PCR Purification kit (QIAGEN Inc).

The PCR products were finally sequenced on an ABI3130 Genetic Analyser (Applied Biosystems), and compared with HXB-2 sequence using SeqScape v2.6 software (Life technologies). All sequences were subjected to quality assessment and determination of DR mutation profile (susceptible, intermediate resistance and resistance) using the Stanford Database (available at http://hivdb.stanford.edu/).

\section{Results}

This study includes 35 HIV-1-infected Djiboutian patients enrolled between October and December 2009. Their mean age was 32.3 years. Among these patients, nineteen patients were ART-naïv (54.2\%) and 16 were first-line ART failures (45.8\%). In ART naïve patients, the median CD4 count was 144 cells/ $\mu$ land the average viral load was $5.58 \log 10 / \mathrm{ml}$ (388 643 copies $/ \mathrm{ml})$. For the patients with first-line ART failure, the median CD4 count was 178 cells $/ \mu \mathrm{l}$, viral loads mean was $5.62 \log 10 / \mathrm{ml}$ and the median time of therapy was 30 months (Table 1 ). There were 20 females (57\%) which were not pregnant at the time of blood collection. Genetic subtyping revealed that $65.7 \%$ of 
samples were infected with subtype C, 20\% with CRF02_AG, $8.5 \%$ with B, 2.9\% with CRF02_AG/C and $2.9 \%$ with $\mathrm{K} / \mathrm{C}$ (Table 2 ).

The ART naive patients showed only NNRTIassociated mutations which were K103N (2 strains) and K101Q (1). No mutations of NRTI were detected. The minor PI mutation L10V was detected in one ART naïve patient [8].

At the time of sampling, all the patients receiving ART were treated by first line. According to the Djiboutian National Program for fighting against AIDS (PNLS) recommendations [9], the first-line treatment consists in 2 NRTI + 1NNRTI. The NRTI backbones were stavudine, zidovudine, and lamivudine. The most used drug combination (12 Patients (75\%)) was AZT/3TC/EFV, while the 6 other patients received either AZT/3TC/NVP, D4T/3TC/EFV or D4T/3TC/NVP. The NRTI-associated mutations were D67N (2 strains), T69N (1), M184V (6), L210W (2), T215Y (2). The NNRTI-associated mutations were K101Q (1), K103N (4), V179E (1), Y181C (1), Y188L (2), G190A (2) (Table 3). For PI-associated mutations, the minor mutation L10V and other polymorphism were detected.

Drug susceptibility results were classified into three categories: susceptible, intermediate resistance and resistance. Of the 16 patients with first-line ART failure, $56.25 \%$ showed resistance to at least one antiretroviral molecule: two patients (12.5\%) were resistant to nucleoside (NRTI), one (6.25\%) to non-nucleoside (NNRTI) reverse transcriptase inhibitors, and six (37.5\%) to both. We found that the resistance rates to Lamivudine and Nevirapine in the 16 patients with first-line ART failure were $37.5 \%$ and $43.75 \%$ respectively. Forty four percent (44\%) of sequences from viral strains did not show any mutation associated to ARV drug resistance- 7out of 16 [10]. Therefore, therapeutic solutions using second line drugs could be proposed to our patients with therapeutic failure and drug resistance mutations.

\section{Discussion}

Minimizing drug resistance to highly active antiretroviral therapy (HAART) is important. First, it maximizes the opportunity for successful second-line and subsequent therapies after viral rebound during first-line treatment;

Table 1 Patients characteristics

\begin{tabular}{lcc}
\hline & $\begin{array}{c}\text { ART-naïve } \\
\text { patients }\end{array}$ & $\begin{array}{c}\text { Patients with } \\
\text { first-line ART failure }\end{array}$ \\
\hline Effectives & 19 & 16 \\
Age (Mean, Years) & 32 & 32.67 \\
CD4 (cells/ $\mu$ l) Mean & 144 & 178 \\
CVp (log 10 copies/ml) Mean & 5.58 & 5.62 \\
\hline
\end{tabular}

second, it limits the transmission of drug-resistant viruses. We report results of the HIV-1 genetic diversity and prevalence of mutations associated with antiretroviral drugs among ART naïve as well as patients who failed first line therapy. The HAART was introduced in Djibouti in 2004. Djibouti, surrounded by Eritrea, Ethiopia, and Somalia, is an important crossroad for trade and exchange.

Our result revealed a majority of subtype C ( 66\%). In fact, Subtype $C$ prevalence has been described in the Horn of Africa[11-14] and a similar prevalence was previously reported in Djibouti in $2005[15,16]$. However, our study describes the subtype B in Djibouti for the first time. It is the predominant subtype in the Western world and the clade that has circulated in North America and Europe. The detection of CRF02_AG strains indicates that they are still circulating in Djibouti, the only country in East Africa in which this recombinant virus was found some years ago $[17,18]$. CRF02_AG recombinant isolates were primarily described in West and Central Africa $[19,20]$. The discordances observed between RT and PR sequences in 2 isolates (CRF02_AG/C, $\mathrm{K} / \mathrm{C}$ ) are probably attributable to the high variability of the genome of HIV in particularly intra subtype recombination within group M subtype C [21].

For the ART naïve patients, the low rate of $\mathrm{CD} 4$ and the high rate of VL can be explain by the fact that $80 \%$ of patients infected by HIV in Djibouti was already detected at an advanced stage of the epidemic according to WHO classification [22,23]. Among the 19 strains, 2 were resistant only to non-nucleoside reverse transcriptase inhibitors (NNRTIs) while one strain showed a minor mutation to PI. Detection of RT and protease mutations associated with drug resistance in individuals who have not been exposed to antiretroviral therapy is thought to result from either transmission from a treated individual.

Concerning first-line ART failures, 38\% of 16 strains sequenced in this group had the M184V mutation. This mutation is selected by lamivudine (3TC), emtricitabine (FTC) or abacavir (ABC) use and confers high-level resistance to 3TC (Figure 1) [24]. Patients receiving incompletely suppressive 3TC regimens usually develop M184V as their first mutation $[25,26]$. Accumulation of the other mutations observed included thymidine associated mutations (including M41L, D67N, K70R, L210W, T215Y/F, K219Q) results in increasing resistance to AZT, Tenofovir, D4T, Abacavir, and DDI $[27,28]$. Two multidrug resistance mutation profiles in general, confer high level drug resistance to all NRTIs. The most common occurring nucleotide excision mutations (NEMs) that confer resistance by enhanced excision [29] were at position 215. The T215Y mutation was observed in $13 \%$ of the sequences while T215F was detected in 6\%. Clinical studies have shown 
Table 2 HIV-1 subtypes and distribution of resistance-associated mutations among 19 ART-naïve patients attending three health centers in Djibouti city between October and December 2009

\begin{tabular}{|c|c|c|c|c|c|c|c|c|}
\hline Patients & SEX & CD4 & $\mathrm{VL}(\mathrm{cp} / \mathrm{mL})$ & SUBTYPE & NRTI & NNRTI & Major Mutation PI & Minor Mutation PI \\
\hline 1 & M & 208 & 170000 & $C$ & None & None & None & None \\
\hline 2 & M & 107 & 4690000 & C & None & None & None & None \\
\hline 3 & F & 186 & 1600000 & CRFO2_AG & None & $\mathrm{K} 103 \mathrm{~N}$ & None & None \\
\hline 4 & M & 167 & 150000 & C & None & None & None & None \\
\hline 5 & F & 195 & 160000 & C & None & None & None & None \\
\hline 6 & $\mathrm{~F}$ & 154 & 98000 & C & None & None & None & None \\
\hline 7 & $\mathrm{~F}$ & 104 & 3360 & CRF02_AG & None & None & None & None \\
\hline 8 & $\mathrm{~F}$ & 47 & 350000 & C & None & K101Q, K103N & None & None \\
\hline 9 & M & 126 & 76000 & CRFO2_AG & None & None & None & L10V \\
\hline 10 & M & 100 & 150000 & C & None & None & None & None \\
\hline 11 & M & 20 & 420000 & CRF02_AG & None & None & None & None \\
\hline 12 & F & 51 & 45000 & KNC & None & None & None & None \\
\hline 13 & $\mathrm{~F}$ & 540 & 260000 & $C$ & None & None & None & None \\
\hline 14 & M & 56 & 43900 & $C$ & None & None & None & None \\
\hline 15 & F & 23 & 663000 & $C$ & None & None & None & None \\
\hline 16 & M & 49 & 185000 & C & None & None & None & None \\
\hline 17 & F & 170 & 87200 & B & None & K101E & None & None \\
\hline 18 & F & 250 & 120000 & $C$ & None & None & None & None \\
\hline 19 & $F$ & 90 & 431000 & C & None & None & None & None \\
\hline
\end{tabular}

Table 3 HIV-1 subtypes and distribution of resistance-associated mutations among 16 patients with first-line ART failure attending three health centers in Djibouti city between October and December 2009

\begin{tabular}{|c|c|c|c|c|c|c|c|c|c|}
\hline $\mathrm{N}^{\circ}$ & SEX & CD4 & SUBTYPE & $\mathrm{VL}(\mathrm{cp} / \mathrm{mL})$ & TREATMENT & NRTI & NNRTI & $\begin{array}{c}\text { Major } \\
\text { Mutation PI }\end{array}$ & $\begin{array}{c}\text { Minor } \\
\text { Mutation PI }\end{array}$ \\
\hline 20 & $\mathrm{~F}$ & 62 & $C$ & 630000 & AZT/3TC/EFV & None & None & None & None \\
\hline 21 & M & 92 & C & 220000 & AZT/3TC/EFV & None & None & None & None \\
\hline 22 & $\mathrm{~F}$ & 346 & C & 1900 & AZT/3TC/EFV & None & None & None & None \\
\hline 23 & M & 176 & C & 21000 & AZT/3TC/EFV & None & None & None & None \\
\hline 24 & $\mathrm{~F}$ & 220 & C & 3270 & AZT/3TC/EFV & None & None & None & None \\
\hline 25 & $F$ & 243 & C & 7500 & AZT/3TC/EFV & None & None & None & None \\
\hline 26 & F & 103 & C & 413000 & D4T/3TC/NVP & None & K101Q, Y181C & None & None \\
\hline 27 & M & 52 & C & 26000 & AZT/3TC/EFV & M184V & $\mathrm{K} 103 \mathrm{~N}$ & None & None \\
\hline 28 & M & 249 & C & 213000 & D4T/3TC/EFV & D67N, M184V, L210W, T215Y & Y188L, G190A & None & None \\
\hline 29 & $\mathrm{~F}$ & 230 & C & 1080000 & AZT/3TC/EFV & $\begin{array}{l}\text { M41L, D67N, L74V, M184V, } \\
\text { L210W, T215Y }\end{array}$ & $\begin{array}{l}\text { K103N, G190A, } \\
\text { H221Y, M230L }\end{array}$ & None & None \\
\hline 30 & F & 140 & CRFO2_AG & 168000 & D4T/3TC/EFV & None & None & None & None \\
\hline 31 & $\mathrm{~F}$ & 250 & CRF02_AG/C & 72720 & AZT/3TC/NVP & K70KR, M184V, K219R & $\mathrm{K} 103 \mathrm{~N}$ & None & None \\
\hline 32 & M & 92 & CRFO2_AG & 21000 & AZT/3TC/EFV & $\mathrm{T} 69 \mathrm{~N}$ & V179E, Y188L & None & L10V \\
\hline 33 & M & 88 & CRFO2_AG & 7100 & AZT/3TC/EFV & M184V & K103N & None & L10V \\
\hline 34 & $\mathrm{~F}$ & 208 & $\mathrm{~B}$ & 1300 & D4T/3TC/NVP & A62V & None & None & None \\
\hline 35 & M & 105 & B & 4837560 & AZT/3TC/EFV & A62V, M184V, T215F, K219Q & None & None & None \\
\hline
\end{tabular}




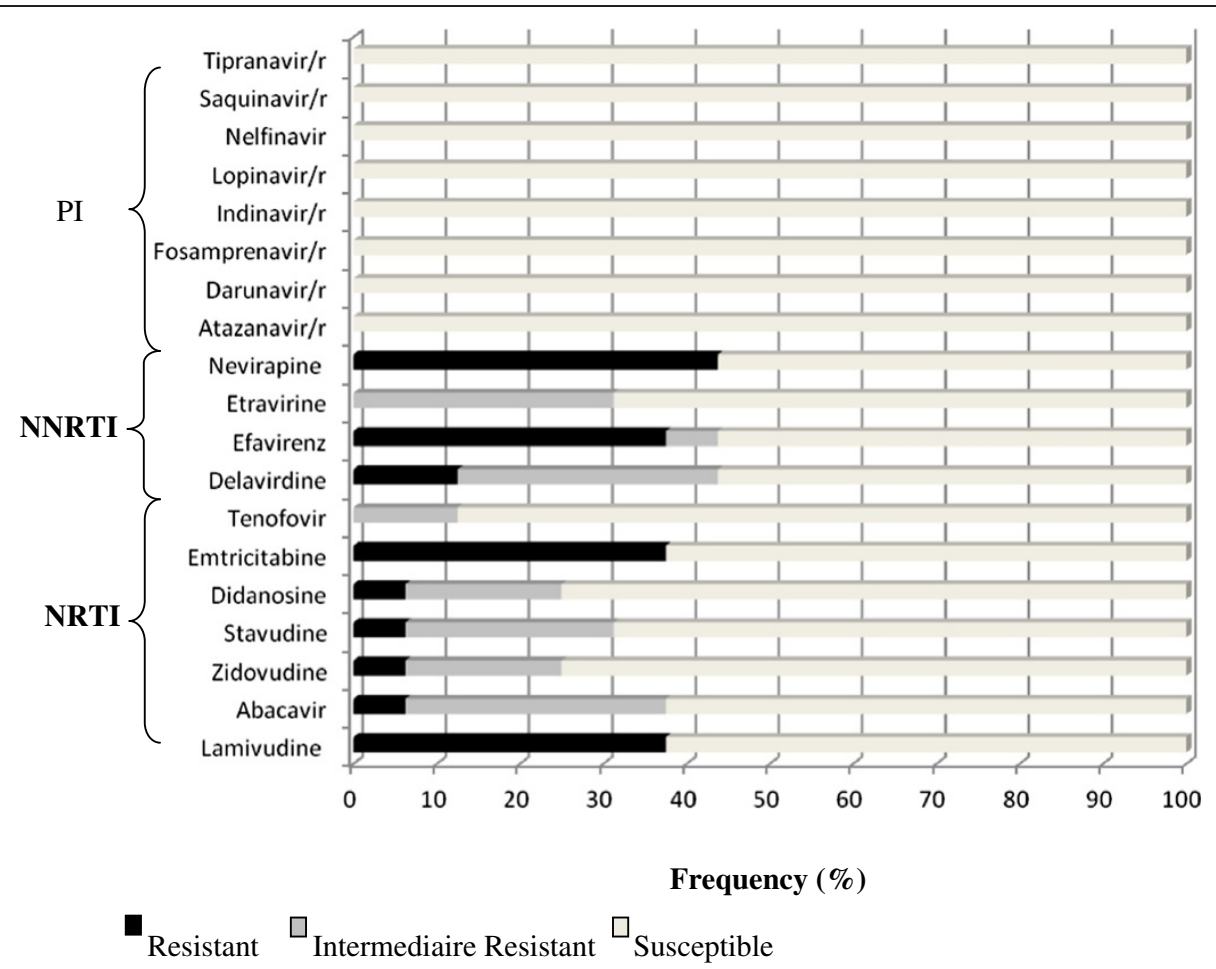

Figure 1 Frequencies of resistance levels to nucleoside (NRTI) and non-nucleoside (NNRTI) reverse transcriptase inhibitors. The horizontal bars indicates the frequency of susceptible (white), intermediate resistance (grey) and resistant (black) samples to NRTI and NNRTI reverse transcriptase inhibitors.

that the NEMs, particularly mutations at position 215, interfere with the clinical response to zidovudine, stavudine, abacavir, didanosine, and most dual NRTI combinations [30]. Mutations conferring resistance to NNRTIs were also seen, with one strain showing resistance only to NNRTIs. The NNRTI resistance-conferring mutations included K103N (25\%), Y188L (12.5\%), Y181C (6\%), G190A (6\%), H221Y (6\%), M230L (6\%). Our data suggest the non-epidemic circulation of resistant viruses, and the absence of multi-class drug resistant viral strains.

It is important to appreciate that resistance at failure is only one factor to consider when choosing an initial HAART regimen. Coformulation, simplicity of administration, price, drug interactions (particularly with tuberculosis therapy), toxicity and adverse events are all important considerations and will differ between patient populations. We noticed seven patients $(\sim 44 \%)$ did not show resistance-conferring mutations and the therapeutic failure may have been due to other factors [31-35]. Information on treatment from their clinic folders allowed us to confirm that for five of these seven cases the ART failure profile was due to poor adherence and for the remaining two cases the detectable viral level was due to coinfection with tuberculosis and malnutrition [36-38].
The escalating rates of transmission of drug resistant virus observed in the past few years, coupled with the poorer response to treatment in persons with drug resistant virus, are being considered as a basis for a recommendation that resistance tests should be performed routinely for persons with new HIV infection [39]. This evaluation, both at the baseline and in follow-up, will be crucial to assess the impact of therapy regimens on resistance development and also their adequation.

\section{Conclusion}

This study reveals primary mutations that confer resistance to NRTI, NNRTI in HIV-1 non-B and B subtype strains, isolated from ART naïve as well as patients who failed first line therapy in Djibouti. It also illustrates the importance of preliminary surveys of drug-resistance mutations in resource-poor countries. Therefore, we suggest the use of resistance testing to check the prevalence of the drug resistance mutation that arises following failure of the first line regimen. This will help in establishing guidelines for second line regimens in Djibouti. This allows the selection of adapted antiretroviral regimens in these regions. Our results provide a basis for repeated epidemiological studies to measure the population effects of HIV treatment programs over time. 


\section{Abbreviations}

ART: Antiretroviral therapy; PR: Protease; RT: Reverse Transcriptase; ARV: Antiretroviral.

\section{Competing interests}

The authors declare that they have no competing interests.

\section{Authors' contributions}

AEA: wrote the manuscript, has made substantial contributions to acquisition of data, or analysis and interpretation of data. AEA and AJ: participated in data analysis and interpretation. HYD and MA BHK: revised the manuscript. AS: proposed the idea, revised the manuscript and save final approval of the version to be published. All authors read and approved the final manuscript

\section{Acknowledgments}

We thank Ali Abdillahi, Nima Ahmed, Mohamed Miganeh, Houssein Yonis and Yacin Ahmed for technical assistance from Djibouti. This work was performed at the National HIV Reference Laboratory, Charles Nicolle Hospital, Tunis, Tunisia. The expert assistance, Assistant Salma ABID, Mme Majda BEN NASR of the laboratory staff is gratefully acknowledged.

\section{Author details}

${ }^{1}$ Laboratoire de la Caisse Nationale de Sécurité Sociale, Djibouti, Republic of Djibouti. 'Laboratoire de Microbiologie, CHU Charles Nicolle, Tunis, Tunisie. ${ }^{3}$ Service des Maladies Infectieuses de l'Hôpital Général Peltier, Djibouti, Republic of Djibouti.

Received: 24 June 2012 Accepted: 18 September 2012 Published: 8 October 2012

\section{References}

1. Robert S, Michael Gottlieb S, Robert S, Howard Schanker M, Joel D, Weisman DO, Peng Thim F, Robert Wolf A, Andrew S: Pneumocystis carinii Pneumonia and Mucosal Candidiasis in Previously Healthy Homosexual Men - Evidence of a New Acquired Cellular Immunodeficiency. N Engl J Med 1981, 305:1425-1431.

2. Barre-Sinoussi $F$, et al: Isolation of a T-lymphotropic retrovirus from a patient at risk for acquired immune deficiency syndrome (AIDS). Science 1983, 220:868-871.

3. Hemelaar J, Gouws E, Ghys PD, Osmanov S: Global trends in molecular epidemiology of HIV-1 during 2000-2007. AIDS 2011, 25:679-689.

4. Thomson MM, Perez-Alvarez L, Najera R: Molecular epidemiology of HIV-1 genetic forms and its significance for vaccine development and therapy. Lancet Infect Dis 2002, 2:461-471.

5. Gilks CF, Crowley S, Ekpini R, et al: The WHO public-health approach to antiretroviral treatment against HIV in resource-limited settings. Lancet 2006, 368(9534):505-510.

6. World Health Organization: Antiretroviral therapy for HIV infection in adults and adolescents: recommendations for a public health approach. Geneva, Switzerland: WHO, HIV Department; 2006. Available at: http://www.who.int/ hiv/pub/guidelines/artadultguidelines.pdf. Accessed 12 December 2007.

7. Gazzard BG, British HIV: Association guidelines for the treatment of HIV-1-infected adults with antiretroviral therapy 2008. HIV Med 2008, 9:563-608

8. Vergne L, Peeters M, Mpoudi-Ngole E, Bourgeois A, Liegeois F, Toure-Kane C, Mboup S, Mulanga-Kabeya C, Saman E, Jourdan J, Reynes J, Delaporte E: Genetic diversity of protease and reverse transcriptase sequences in non-subtype $B$ human immunodeficiency virus type 1 strains: evidence of many minor drug resistance mutations in treatment-naive patients. J Cardiovasc Manag 2000, 38:3919-3925.

9. Guide d'utilisation des Antirétroviraux (ARV) chez l'adulte et l'adolescent en République de DJIBOUTI: 2008. http://www.aidstar-one.com/sites/default/ files/treatment/national_treatment_guidelines/Djibouti_adult_guidelines_ 2008.pdf.

10. Jlizi A, Ben Ammar A, El Gaaied A, Slim F, Tebourski M, Ben Mamou T, Ben $C$, et al: Profile of drug resistance mutations among HIV-1-infected Tunisian subjects failing antiretroviral therapy. Arch Virol 2008, 153:1103-1108.

11. Abecasis $A B$, Vandamme AM, Lemey P: Quantifying differences in the tempo of human immunodeficiency virus type 1 subtype evolution. J Virol 2009, 83:12917-12924.
12. Nyombi BM, et al: Diversity of human immunodeficiency virus type 1 subtypes in Kagera and Kilimanjaro regions Tanzania. AIDS Res Hum Retroviruses 2008, 24:761-769.

13. Abebe A, Lukashov W, Pollakis G, Kliphuis A, Fontanet AL, Goudsmit J, Rinke TF, de Wit TF: Timing of the HIV-1 subtype C epidemic in Ethiopia based on early virus strains and subsequent virus diversification. AIDS 2001, 15:1555-1561.

14. Abebe A, Lukashov W, Rinke De Wit TF, Fisseha B, Tegbaru B, Kliphuis A, Tesfaye G, Negassa H, Fontanet AL, Goudsmit J, Pollakis G: Timing of the introduction into Ethiopia of subcluster $C^{\prime}$ of HIV type 1 subtype $C$. AIDS Res Hum Retrovir 2001, 17:657-661.

15. Maslin J, Rogier C, Caron M, Grandadam M, Koeck JL, Nicand E: Antiretroviral drug resistance among drug-naive HIV-1-infected individuals in Djibouti (Horn of Africa). Antivir Ther 2005, 10:855-859.

16. Maslin J, Rogier C, Berger F, Khamil MA, Mattera D, Grandadam M, Caron M, Nicand E: Epidemiology and genetic characterization of HIV-1 isolates in the general population of djibouti (Horn of Africa). J Acquir Immune Defic Syndr 2005, 39:129-132.

17. Faria NR, Suchard MA, Abecasis A, Sousa JD, Ndembi N, Bonfim I, Camacho RJ, Vandamme AM, Lemey P: Phylodynamics of the HIV-1 CRF02_AG clade in Cameroon. Infect Genet Evol 2012, 12(2):453-460.

18. Hemelaar J, et al: The origin and diversity of the HIV-1 pandemic. Trends in Molecular Medicine 2011, 20:1-11.

19. Carr JK, Salminen MO, Albert J, Sanders-Buell E, Gotte D, Birx DL, McCutchan FE: Full genome sequences of human immunodeficiency virus type 1 subtypes $G$ and A/G intersubtype recombinants. Virology 1998, 247:22-31.

20. Cornelissen M, van Den Burg R, Zorgdrager F, Goudsmit J: Spread of distinct human immunodeficiency virus type 1 AG recombinant lineages in Africa. J Gen Virol 2000, 81:515-523.

21. Rousseau CM, Learn GH, Bhattacharya T, Nickle DC, Heckerman D, Senica C, Christian B, Philip J, Goulder R, Bruce D, Walker Photini K, Korber BT, Mullins J: Extensive Intra-subtype Recombination in South African HIV-1 Subtype C Infections. J Virol 2007, 81(9):4492-4500.

22. Darar HY, Kibangou N, Mbuzenakamwe MJ, Goulan MA, Ibrahim IM: Réponse au traitement antirétroviral chez les patients infectés par le VIH-1 suivis au Centre Yonis Toussaint de Djibouti [Abstract]. 5éme Conférence Francophone VIH/SIDA, Maroc 2010, 493(77):215. 28-31 March 2010.

23. Kibangou N: Prise en charge des patients sous traitement ARV à Djibouti entre 2004 et 2009 [Abstract]. Séme Conférence Francophone VIH/SIDA, Maroc 2010, 578(88):237. 28-31 March 2010.

24. Johnson VA, Vincent C, Günthard HF, Roger P, Deenan P, Robert S, Wensing AM, Richman DD: 2011 update of the drug resistance mutations in HIV-1. Top Antivir Med 2011, 19:156-164.

25. Geretti AM: Clinical implications of HIV drug resistance to nucleoside and nucleotide reverse transcriptase inhibitors. AIDS Rev 2006, 8:210-220.

26. Theys K, Deforche K, Libin P, Camacho RJ, Van Laethem K, Vandamme AM: Resistance pathways of human immunodeficiency virus type 1 against the combination of zidovudine and lamivudine. J Gen Virol 2010, 91:1898-1908.

27. Van Vaerenbergh K, Van Laethem K, Albert J, Boucher CA, Clotet B, Floridia M, Gerstoft J, Hejdeman B, Nielsen C, Pannecouque C, Perrin L, Pirillo MF, Ruiz L, Schmit JC, Schneider F, Schoolmeester A, Schuurman R, Stellbrink HJ, Stuyver L, Van Lunzen J, Van Remoortel B, Van Wijngaerden E, Vella S, Witvrouw M, Yerly S, De Clercq E, Destmyer J, Vandamme AM: Prevalence and characteristics of multinucleoside-resistant human immunodeficiency virus type 1 among European patients receiving combinations of nucleoside analogues. Antimicrob Agents Chemother 2000, 44:2109-2117.

28. Coakley EP, Gillis JM, Hammer SM: Phenotypic and genotypic resistance patterns of HIV-1 isolates derived from individuals treated with didanosine and stavudine. AIDS 2000, 14:F9-F15.

29. Shafer RW: Genotypic testing for human immunodeficiency virus type 1 drug resistance. Clin Microbiol Rev 2002, 15:247-277.

30. Emanuele B, Ana PC M, Victor Moreschi N, Camila DA S, Karla A, Saito AO, Mecatti MC, Santos MG, Pimentel CR, Larissa LG S, Cruz CR, de Noronha L: Histomorphometric and immunohistochemical analysis of infectious agents, T-cell subpopulations and inflammatory adhesion molecules in placentas from HIV-seropositive pregnant women. Diagn Pathol 2011, 6(101):101. 24 October 2011. 
31. Eholie SP, N'Dour CT, Cisse M, Bissagnene E, Girard PM: Observance of antiretroviral treatments African specificities. Med Mal Infect 2006 , 36:443-448.

32. Phillips AN, Dunn D, Sabin C, et al: UK Collaborative Group on HIV Drug Resistance, UK CHIC Study Group. Long term probability of detection of HIV-1 drug resistance after starting antiretroviral therapy in routine clinical practice. AIDS 2005, 19:487-494.

33. Chesney MA, Ickovics J, Hecht FM, et al: Adherence: a necessity for successful HIV combination therapy. AIDS 1999, 13(A):S271-S278.

34. Bangsberg DR, Charlebois ED, Grant RM, et al: High levels of adherence do not prevent accumulation of HIV drug resistance mutations. AIDS 2003, 17:1925-1932.

35. Shah B, Walshe L, Saple DG, et al: Adherence to antiretroviral therapy and virologic suppression among HIV-infected persons receiving care in private clinics in Mumbai, India. Clin Infect Dis 2007, 44:1235-1244.

36. Ahmed AA, Katlama C, Ghosn J, Guiguet M, Costagliola D: Évaluation de l'observance au traitement antirétroviral au sein d'une cohorte de 200 patients à Djibouti (2005). Eastern Mediterranean Health Journal 2007, 13(6):1286-1297.

37. Renoux E, Barreh Matan A, Sevre JP, et al: Tuberculose et infection VIH: expérience du programme national de lutte antituberculeuse de Djibouti: 1990-1996. Med Trop 2002, 62:171-176.

38. Acina E, Morand C, Mahdi A, Morand JJ: La malnutrition en République de Djibouti: un problème majeur de santé publique. Revue de I'ISERST 1991, 5:11-15.

39. Little SJ, Holte S, Routy JP, et al: Antiretroviral-drug resistance among patients recently infected with HIV. New Engl J Med 2002, 347:385-394.

doi:10.1186/1746-1596-7-138

Cite this article as: Elmi Abar et al:: HIV-1 drug resistance genotyping from antiretroviral therapy (ART) naïve and first-line treatment failures in Djiboutian patients. Diagnostic Pathology 2012 7:138.

\section{Submit your next manuscript to BioMed Central and take full advantage of:}

- Convenient online submission

- Thorough peer review

- No space constraints or color figure charges

- Immediate publication on acceptance

- Inclusion in PubMed, CAS, Scopus and Google Scholar

- Research which is freely available for redistribution 